\title{
Optimal and/or Efficient Two treatment Crossover Designs for Five Carryover Models
}

\author{
${ }^{1}$ Statistics, Gujarat Commerce college, Ellisbridge, Ahmedabad, Gujarat, India, E-mail: jjgondaliya@gmail.com. \\ http://orcid.org/0000-0002-8302-5814. \\ ${ }^{2}$ Statistics, Sardar Patel University, Vallabh Vidyanagar, Gujarat, India
}

\begin{abstract}
:
Crossover designs robust to changes in carryover models are useful in clinical trials where the nature of carryover effects is not known in advance. The designs have been characterized for being optimal and efficient under no carryover-, traditional-, and, self and mixed carryover- models, however, ignoring the number of subjects, which has significant impact on both optimality and administrative convenience. In this article, adding two more practical models, the traditional, and, self and mixed carryover models having carryover effect only for the new or test treatment, a $5 \mathrm{M}$ algorithm is presented. The $5 \mathrm{M}$ algorithm based computer code searches all possible two treatment crossover designs under the five carryover models and list those which are optimal and /or efficient to all the five carryover models. The resultant exhaustive list consists of optimal and/or efficient crossover designs in two, three, and four periods, having 4 to 20 subjects of which 24 designs are new optimal for one of the established carryover models, and 34 designs are optimal for newly added models.
\end{abstract}

Keywords: self and mixed carryover effect, optimal design, repeated measurement, standard treatment, traditional model

DOI: $10.1515 / \mathrm{ijb}-2018-0001$

Received: January 2, 2018; Revised: July 8, 2018; Accepted: October 27, 2018

\section{Introduction}

Many diseases and conditions are studied in clinical trials using crossover design (COD) because within subject treatment comparisons are more efficient than between subject treatment comparisons. On the other hand, since in crossover, each subject receive a sequence of treatments as specified by the design over successive periods of time, the carryover effects are natural and may sustain for different amounts of time. According to Senn [1] if carryover is present to any appreciable degree then the usual statistical models provide no guaranteed protection against its effects. Owing to this reason, Senn and Lambrou [2] investigated two treatments four periods CODs under traditional and steady state carryover models and concluded that statistician cannot provide a general design and estimation strategy that give guarantee to deal with carryover. The steady state model assumes that self carryover ultimately vanishes to zero. R. Kempton and David [3] showed that COD \{AB,BA\} is $\bar{A}$-optimal and COD $\{\mathrm{ABB}, \mathrm{BAA}\}$ is MA-optimal when carryover effects are proportional to treatment effects. Since proving optimality through combinatorial theory is tractable only for restricted class of designs, many authors, Jones and Donev [4], J. John and Whitaker [5], Yang and Stufken [6], S. Satpati and Aggarwal [7] etc. used computer search algorithm to construct two and more treatments optimal CODs for specific models.

A design that is optimal for one statistical model may not be optimal for another, and, design that estimate treatment contrasts under one model may not estimate under another. It is therefore of interest to identify designs that provide efficient estimates (relative to an optimal design) for more than one model.

Hedayat and Stufken [8] studied CODs in $t$ treatments having two to four periods under two carryover models and identified optimal and efficient CODs. Ozan and Stufken [9] assessed the impact of carryover effects on the variances of the estimators of treatment differences in CODs for several models. They suggested that one should use a design that produces estimates with smaller values of variances relative to other designs with the same number of treatments and periods for all or most of the models under consideration. However, these authors did not consider the number of subjects while comparing different designs, which in fact is an important parameter and has a significant impact, not only on the choice of an optimal design but also in the execution of crossover experiment. In particular for experiments comparing a new treatment with a standard treatment, two more kinds of carryover models are likely to exist, the traditional carryover model and the self 
and mixed carryover model with only new treatment yielding carryover effect. These two novel considerations, the number of subjects, and the models, have expanded the spectrum of the design development of many a class of CODs.

In this paper, optimal and/or efficient two treatment crossover designs are obtained for the five mentioned carryover models through the computer code written based on presented $5 \mathrm{M}$ algorithm. After exhaustive search, it lists only optimal and/or efficient crossover designs in the class specified by the number of periods and subjects. The COD which is either optimal for any one model and efficient for the remaining models or efficient for all five models is referred as optimal and/or efficient COD. Our contribution is in two way. One is to new optimal crossover design in specific model and second is new optimal and/or efficient crossover design to all five model. A list of new optimal and/or efficient two period CODs in 6 to 20 subjects, three period CODs in 8 to 20 subjects, and four period CODs in 10 to 20 subjects have been provided. For example, in the class of $\mathrm{COD}(2,6,3),\{2 \mathrm{ABA}, \mathrm{ABB}, 2 \mathrm{BAB}, \mathrm{BAA}\}$ is new optimal under self and mixed carryover model, replacing $\{3 \mathrm{ABA}$, $3 \mathrm{BAB}\}$.

\section{Models and optimality criterion}

\subsection{Models}

The model known as no carryover model in the COD literature is of the form,

$$
y_{i j k}=\mu+\pi_{k}+\xi_{i j}+\tau_{d(k, j)}+\epsilon_{i j k}, \quad i=1, \ldots, s ; j=1, \ldots, n_{i} ; k=1,2, \ldots, p,
$$

where, $y_{i j k}$ denotes the response from sequence $i$, subject $j$, in period $k$ to which treatment $d(k, j)$ was assigned, $\mu$ is the general mean, $\tau_{d(k, j)}$ is the effect of treatment $d(k, j), \pi_{k}$ is the effect due to period $k, \xi_{i j}$ is the effect due to subject $j$ having sequence $i$, every sequence replicated $n_{i}$ times $\left(n_{i} \geq 1\right)$, and the $\epsilon_{i j k}$ are independently normally distributed error term with mean 0 and variance $\sigma^{2}$.

When the response variable is also affected by the treatment applied in the previous period, then one more term fixed carryover effect of the treatment should be added in the model. This model generally called simple carryover model or traditional model in optimal design literature is given by

$$
y_{i j k}=\mu+\pi_{k}+\xi_{i j}+\tau_{d(k, j)}+\gamma_{d(k-1, j)}+\epsilon_{i j k}
$$

Where, $\gamma_{d(k-1, j)}$ is the carryover effect of treatment $d(k-1, j)$ on the response observed on subject $j$ in period $k$. It is obvious that there is no carryover effect in the first period, that is, $\gamma_{d(0, j)}=0$. Sometime carryover due to treatment preceded by itself in the previous period is different than treatment proceeded by other. This view was first introduced by Afsarinejad and Hedayat [10] and studied by Kunert and Stufken [11, 12]. This self and mixed carryover effect is of the form,

$$
y_{i j k}=\mu+\pi_{k}+\xi_{i j}+\tau_{d(k, j)}+\gamma_{1 d(k-1, j)}+\gamma_{2 d(k-1, j)}+\epsilon_{i j k}
$$

Where, $\gamma_{1 d(k-1, j)}$ is the carryover of treatment preceded by other treatment in the previous period and $\gamma_{2 d(k-1, j)}$ is the carryover of treatment preceded by itself in the previous period. When the purpose of a trial is to compare a new drug with a standard drug or a placebo, the experimenter is usually aware of the washout period of the standard treatment. In this case, if the experimenter set the length of washout period according to the standard treatment then the standard treatment would not have carryover effect. As regards the complexity of the analysis of crossover experiments for comparing new treatment with a standard, the analysis get simplified by assuming that only the new treatment has carryover effect but the standard treatment does not. The traditional model with this assumption is referred as traditional model with only treatment A has carryover effect, is model 2 with $\gamma_{d(k-1, j)}=0$ if $d(k-1, j)=B$.

Similarly, self and mixed effect model with this assumption is referred as self and mixed model with only treatment A has carryover effect, is model 3 with $\gamma_{d(k-1, j)}=0$ if $d(k-1, j)=B$.

We will refer to the no carryover effects model as NCM, the traditional model as TBM, the self and mixed carryover effects model as SBM, the traditional model with only treatment A has carryover effects as TSM, and, the self and mixed model with only treatment A has carryover effects as SSM.

\subsection{Optimality criterion}

Most commonly the performance of a design is measured by its variance of treatment comparison, given by the variance of the least square estimates of the treatments. Usually a design $d$ with larger information matrix, 
$C_{d}$, yields smaller variance for estimate of treatment, hence the central problem in the design of experiments is to find the design $d$ such that the information matrix $C_{d}$ is as large as possible. However, matrices cannot be compared directly in general. To compare them for different designs, one has to define functions of $C_{d}$, which maps from the matrix space into one dimensional space. For the connected, balanced designs it suffices to compare variances of the treatment contrasts. Note that, the nature of treatment contrasts is depends upon the objective of the study.

For two treatments, the objective is generally estimating difference of treatment effects. The design which minimizes its variance over all possible designs for a specific class is referred to the optimal in the class (See, Jones and Donev [4], Hedayat and Stufken [8], etc.). A specific class of COD is generally determined by fixing only some of the three parameters, the number of treatments, periods and subjects, but preferably, it should be considered by fixing all the three parameters.

Hedayat and Stufken [8], Ozan and Stufken [9] etc. considered the number of distinct sequences instead of the number of subjects in comparing different designs, and thus missed several optimal designs available in specific number of subjects, particularly for $n \equiv 2(\bmod 4)$ in the presence of carryover effects. In their designs the number of subjects is equal to a sum of equi-replicated distinct sequences. In Table 1, the designs having serial numbers 3 and 8 are new optimal designs under TBM respectively for eighteen and twenty subjects, but they are not optimal under modified model, TSM. Under TSM, the designs having serial numbers 2 and 7 are optimal designs. Thus, in general, a design that is optimal under one model may not be optimal under another model. Then better choice is the design which is efficient under several models. The efficiency is the relative efficiency of a design, $d$, with respect to the optimal design for that class and the model. Efficiency is calculated by taking ratio of the variances of least squares estimator of treatment contrast for the optimal design to the variance of design $d$. Thus, efficiency of a design optimal for a specified class and model is $100 \%$ but it may not be so in case of another models. From Table 1, it is clear that efficiency of design bearing serial number 1 is $89 \%$ as compared to the design bearing serial numbers 2 which is optimal in the class $\operatorname{COD}(2,18,3)$ under TSM.

Table 1: Optimal and/or Efficient balanced crossover designs for classes $\operatorname{COD}(2,18,3)$ and $\operatorname{COD}(2,20,3)$.

\begin{tabular}{|c|c|c|c|c|c|c|c|}
\hline Serial no. & Crossover Design & $\mathbf{n}$ & NCM & TSM & TBM & SSM & SBM \\
\hline 1 & $4 \mathrm{AAB}, \mathrm{ABA}, 4 \mathrm{ABB}, 4 \mathrm{BAA}, \mathrm{BAB}, 4 \mathrm{BBA}$ & 18 & 100 & 89 & 86 & 75 & 70 \\
\hline 2 & $\mathrm{AAA}, 2 \mathrm{AAB}, 5 \mathrm{ABA}, \mathrm{ABB}, 3 \mathrm{BAA}, 3 \mathrm{BAB}, 3 \mathrm{BBB}$ & 18 & 78 & 100 & 58 & 46 & 69 \\
\hline 3 & $3 \mathrm{AAB}, 6 \mathrm{ABA}, 3 \mathrm{BAA}, 3 \mathrm{BAB}, 3 \mathrm{BBB}$ & 18 & 83 & 51 & 100 & 27 & 62 \\
\hline 4 & $5 \mathrm{AAA}, 4 \mathrm{ABB}, 4 \mathrm{BAB}, 4 \mathrm{BBA}, \mathrm{BBB}$ & 18 & 67 & 75 & 73 & 100 & 49 \\
\hline 5 & $2 \mathrm{AAA}, 3 \mathrm{AAB}, 4 \mathrm{ABB}, 4 \mathrm{BAA}, 3 \mathrm{BBA}, 2 \mathrm{BBB}$ & 18 & 78 & 73 & 70 & 65 & 100 \\
\hline 6 & 3АAB,7ABB,7BAA,3BВA & 20 & 100 & 94 & 96 & 69 & 40 \\
\hline 7 & 8АAB,2АBA,2BAA,6BВA,2BBB & 20 & 90 & 100 & 86 & 21 & 28 \\
\hline 8 & $6 \mathrm{AAB}, 3 \mathrm{ABA}, \mathrm{ABB}, 4 \mathrm{BAA}, 3 \mathrm{BBA}, 3 \mathrm{BBB}$ & 20 & 85 & 70 & 100 & 33 & 33 \\
\hline 9 & $4 \mathrm{AAA}, 3 \mathrm{AAB}, 3 \mathrm{ABB}, \mathrm{BAA}, 2 \mathrm{BAB}, 5 \mathrm{BBA}, 2 \mathrm{BBB}$ & 20 & 70 & 59 & 60 & 100 & 35 \\
\hline 10 & 9ABA,ABB,BAA,9BAB & 20 & 100 & 37 & 38 & 29 & 100 \\
\hline
\end{tabular}

\section{The $5 \mathrm{M}$ algorithm}

In this section, we present a computer algorithm for search of optimal and/or efficient CODs under the five models, namely, NCM, TSM, TBM, SSM and SBM. The algorithm involves making comparisons of variances of direct effects among CODs of a class for the given model. Several computer algorithms have been given in literature (Jones and Donev [4], J. John and Whitaker [5], Yang and Stufken [6], S. Satpati and Aggarwal [7], etc.) for search of optimal and/or efficient CODs. The most common approach of these algorithms is that, they begin the search procedure with a 'random' design and attempt to improve it until cannot be improved by applying further steps. Our computer search algorithm starts from the first, trivial possibility, proceeds systematically up to the last possibility, and provides globally optimum COD by comparing every possible CODs of the specified class and model. Since, the algorithm makes exhaustive search and returns optimal and/or efficient crossover designs for one or more of the five models, the computer programming was challenging. A broad outline of the $5 \mathrm{M}$ algorithm is given below.

i. Set variance $V(m)=$ a high value (say, 99), for all models numbered $m=1, \ldots, 5$. Set parameters $t, p$ and $n$.

ii. Generate all possible treatment sequences of $t$ treatments in $p$ periods. 
iii. Generate a crossover design $d$ by considering $n$ treatment sequences arbitrarily from those obtained in step (ii) including replications of the sequences.

iv. Perform equal replication check for the generated design, that is, $(n p) / v$ occurrence of each treatment. If all the treatments are not equally replicated then return to step (iii).

v. Perform balanced occurrence check for treatments in each period, that is, $n / v$ occurrence of each treatment in each period. If all the treatments are not equally replicated in each period then return to step (iii).

vi. Perform pair wise balanced occurrence of treatments in two successive periods, that is, each ordered pair of distinct treatments, as well as, each self pair of treatments are given to constant number of units. If this condition is not satisfied then return to step (iii).

vii. Under NCM, TSM, TBM, SSM and SBM indexed respectively $m=1,2, \ldots, 5$.

a. Perform connectedness check for the design $d$, that is, calculate the rank of the design information matrix $\left(C_{d}\right)$ under model $m$. If it is not connected, that is, rank of $C_{d}$ is less than $t-1$, then skip next step and consider next model.

b. Perform least variance check, that is, compute variances of the least squares estimator of treatment contrasts $V(d, m)$ under model $m$. If $(V(d, m)>=0 \& V(d, m)<V(m))$ then store $V(m)=V(d, m)$ and optimaldesign $(m)=d$.

viii. Finally, store the design with variance $V(d, m)$ and ranks of the design matrix under NCM, TSM, TBM, SSM and SBM, provided, the design is connected in all five models.

ix. Repeat (iii) to (viii) for all possible combinations of $n$ treatment sequences.

This algorithm produces optimal CODs under each model along with their variances and ranks. All this is stored in a spreadsheet for a glance view of design statistics for optimal and/or efficient CODs under given model. Note that CODs optimal under NCM, TSM, TBM, SSM and SBM are stored respectively as the last five designs in the spreadsheet.

\subsection{Working of the $5 \mathrm{M}$ algorithm}

Consider an experimental situation where $t=2, p=2, n=2$. Let the two treatments are denoted by 1 , 2 . Step (i) set $V(m)=15, m=1,2, \ldots, 5$. Step (ii) Generate all possible sequences, say, 11, 12, 21, 22. Step (iii) Generates a design say, $\{11,11\}$. As per step (iv) treatment 2 is not equally replicated as treatment 1 and hence, algorithm returns to step (iii) and generates second design say, $\{11,12\}$. Again algorithm shall return to step (iii) and generates designs, say, $\{11,21\}$ then $\{11,22\}$. Now algorithm moves to step (v) but all the treatments are not equally replicated in each period and hence algorithm returns to step (iii) and generate the other design $\{12$, 12\}. Further algorithm moves from step (v) to step (iii) and generate design $\{12,21\}$. Now this design satisfies condition of steps (iv)-(vi). Hence in step (viia), rank of $C_{d}$ under NCM is calculated. Here rank of the design matrix is one, that is, design is connected. In step (viib) variances of the least squares estimator of treatment contrasts under NCM is calculated. Also variances of the least squares estimator of treatment contrasts is less than the set variance $\mathrm{V}(1)$. Hence algorithm stores design $\{12,21\}$ as optimal design along with its variance for treatment comparison. Similarly, algorithm calculates $C_{d}$ and variances of the least squares estimator of treatment contrasts under TSM, TBM, SSM and SBM one by one according to step (vii). Under all the other four models, design is not connected and hence algorithm moves to step (ix). According to step (ix), algorithm returns to step (iii) and generate the other designs. Similarly algorithm repeatedly works for other sequence combinations $\{12,22\},\{21,21\},\{21,22\}$ and $\{22,22\}$. Since all fail to yield any design, the design $\{12,21\}$ optimal under NCM is stored along with the variance of treatment contrast and ranks under NCM, TSM, TBM, SSM and SBM. Finally algorithm generates spreadsheet having three sheets named as var, rank and design, respectively, showing the variances of treatment contrast, the ranks of $C_{d}$ matrix and the CODs, stored by the $5 \mathrm{M}$ algorithm.

\section{Two treatment two period CODs}

In this case, only a few designs are available which can estimates treatment contrast unbiasedly, because the resultant design is a collection of replicates of only four possible sequences, $\mathrm{AB}, \mathrm{BA}, \mathrm{AA}$ and $\mathrm{BB}$. According to step (v) of $5 \mathrm{M}$ algorithm, all these two treatment CODs are balanced over periods with $n / 2$ occurrences of both treatments and therefore the number of subjects $n$ is necessarily even. 


\subsection{Optimal CODs under NCM}

It has been well established that the design in replicates of two sequences $\{\mathrm{AB}, \mathrm{BA}\}$ is optimal under NCM. That is, when availability of subjects is $n$, experimenter uses $n / 2$ replications of design $\{A B, B A\}$. The optimality of design remains unaffected under $\mathrm{NCM}$, for example, cod27\{7AB, 7BA\} is optimal under NCM in the class $\operatorname{COD}(2,14,2)$. For simplicity, we use an abbreviated notation for the designs. The number after cod stands for serial number of the crossover design in the tables listing CODs. The number before the sequence denotes the replication of that sequence in the design.

\subsection{Optimal CODs under TSM, TBM and SSM}

Crossover design in treatment sequences $\mathrm{AB}, \mathrm{BA}$ is optimal under $\mathrm{NCM}$, but it cannot estimate treatment contrast under other models. This design has been criticized by many authors for being unsuitable under carryover models. As an alternative, a COD with all four sequences $\{\mathrm{AB}, \mathrm{BA}, \mathrm{AA}, \mathrm{BB}\}$ has been suggested for estimation under TBM. It is also optimal for the class $\operatorname{COD}(2,4,2)$ because no other design is available. This restricts experimenters to consider number of subjects in multiple of four, and overlooks the possibilities of classes $C O D(2,6,2)$, $\operatorname{COD}(2,10,2), \operatorname{COD}(2,14,2), \operatorname{COD}(2,18,2)$ and so on. So far, no COD has been studied under TSM, which are incidentally the same designs as those optimal under TBM. In Table 2, cod12, cod15 and others are optimal under both TSM and TBM.

Table 2: Optimal and/or Efficient balanced crossover designs for classes $\operatorname{COD}(2,6,2)$ to $\operatorname{COD}(2,20,2)$.

\begin{tabular}{|c|c|c|c|c|c|c|c|}
\hline Serial no. & Crossover Design & $\mathbf{n}$ & NCM & TSM & TBM & SSM & SBM \\
\hline 11 & $3 \mathrm{AB}, 3 \mathrm{BA}$ & 6 & 100 & - & - & - & - \\
\hline 12 & 2AA,AB,BA,2BB & 6 & 33 & 100 & 100 & 100 & - \\
\hline 13 & $\mathrm{AA}, 2 \mathrm{AB}, 2 \mathrm{BA}, \mathrm{BB}$ & 6 & 67 & $100^{\bullet}$ & $100^{\bullet}$ & $100^{*}$ & - \\
\hline 14 & 3AA,AB,BA,3BB & 8 & 25 & 75 & 75 & 75 & - \\
\hline 15 & $2 \mathrm{AA}, 2 \mathrm{AB}, 2 \mathrm{BA}, 2 \mathrm{BB}$ & 8 & 50 & 100 & 100 & $100^{*}$ & - \\
\hline 16 & $\mathrm{AA}, 3 \mathrm{AB}, 3 \mathrm{BA}, \mathrm{BB}$ & 8 & 75 & 75 & 75 & 75 & - \\
\hline 17 & $4 \mathrm{AB}, 4 \mathrm{BA}$ & 8 & 100 & - & - & - & - \\
\hline 18 & $2 \mathrm{AA}, 3 \mathrm{AB}, 3 \mathrm{BA}, 2 \mathrm{BB}$ & 10 & 60 & $100^{\bullet}$ & $100^{\bullet}$ & $100^{*}$ & - \\
\hline 19 & $\mathrm{AA}, 4 \mathrm{AB}, 4 \mathrm{BA}, \mathrm{BB}$ & 10 & 80 & 67 & 67 & 67 & - \\
\hline 20 & $5 \mathrm{AB}, 5 \mathrm{BA}$ & 10 & 100 & - & - & - & - \\
\hline 21 & $3 \mathrm{AA}, 3 \mathrm{AB}, 3 \mathrm{BA}, 3 \mathrm{BB}$ & 12 & 50 & 100 & 100 & 100 & - \\
\hline 22 & $2 \mathrm{AA}, 4 \mathrm{AB}, 4 \mathrm{BA}, 2 \mathrm{BB}$ & 12 & 67 & 89 & 89 & 89 & - \\
\hline 23 & $\mathrm{AA}, 5 \mathrm{AB}, 5 \mathrm{BA}, \mathrm{BB}$ & 12 & 83 & 56 & 56 & 56 & - \\
\hline 24 & $6 \mathrm{AB}, 6 \mathrm{BA}$ & 12 & 100 & - & - & - & - \\
\hline 25 & $2 \mathrm{AA}, 5 \mathrm{AB}, 5 \mathrm{BA}, 2 \mathrm{BB}$ & 14 & 71 & 83 & 83 & 83 & - \\
\hline 26 & $\mathrm{AA}, 6 \mathrm{AB}, 6 \mathrm{BA}, \mathrm{BB}$ & 14 & 86 & 50 & 50 & 50 & - \\
\hline 27 & $7 \mathrm{AB}, 7 \mathrm{BA}$ & 14 & 100 & - & - & - & - \\
\hline 28 & $3 \mathrm{AA}, 4 \mathrm{AB}, 4 \mathrm{BA}, 3 \mathrm{BB}$ & 14 & 57 & $100^{\bullet}$ & $100^{\bullet}$ & $100^{*}$ & - \\
\hline 29 & $4 \mathrm{AA}, 3 \mathrm{AB}, 3 \mathrm{BA}, 4 \mathrm{BB}$ & 14 & 43 & 100 & 100 & 100 & - \\
\hline 30 & $3 \mathrm{AA}, 5 \mathrm{AB}, 5 \mathrm{BA}, 3 \mathrm{BB}$ & 16 & 63 & 94 & 94 & 94 & - \\
\hline 31 & 2AA,6AB,6BA,2BB & 16 & 75 & 75 & 75 & 75 & - \\
\hline 32 & $\mathrm{AA}, 7 \mathrm{AB}, 7 \mathrm{BA}, \mathrm{BB}$ & 16 & 87 & 44 & 44 & 44 & - \\
\hline 33 & $8 \mathrm{AB}, 8 \mathrm{BA}$ & 16 & 100 & - & - & - & - \\
\hline 34 & $4 \mathrm{AA}, 4 \mathrm{AB}, 4 \mathrm{BA}, 4 \mathrm{BB}$ & 16 & 50 & 100 & 100 & 100 & - \\
\hline 35 & $4 \mathrm{AA}, 5 \mathrm{AB}, 5 \mathrm{BA}, 4 \mathrm{BB}$ & 18 & 56 & $100^{\bullet}$ & $100^{\bullet}$ & $100^{*}$ & - \\
\hline 36 & $3 \mathrm{AA}, 6 \mathrm{AB}, 6 \mathrm{BA}, 3 \mathrm{BB}$ & 18 & 67 & 90 & 90 & 90 & - \\
\hline 37 & 2AA,7AB,7BA,2BB & 18 & 78 & 70 & 70 & 70 & - \\
\hline 38 & $9 \mathrm{AB}, 9 \mathrm{BA}$ & 18 & 100 & - & - & - & - \\
\hline
\end{tabular}




\begin{tabular}{llllllll}
39 & 5AA,5AB,5BA,5BB & 20 & 50 & 100 & 100 & $100^{*}$ & - \\
40 & 4AA,6AB,6BA,4BB & 20 & 60 & 96 & 96 & 96 & - \\
41 & 3AA,7AB,7BA,3BB & 20 & 70 & 84 & 84 & 84 & - \\
42 & 2AA,8AB,8BA,2BB & 20 & 80 & 64 & 64 & 64 & - \\
43 & 10AB,10BA & 20 & 100 & - & - & - & - \\
\hline
\end{tabular}

Design in bold denote new optimal and/or efficient COD to class having $n$ number of subjects

${ }^{*}$ New Optimal COD under new defined model SSM

- New Optimal COD under TSM and TBM

In literature, not a single two treatment two period COD is available which can estimate treatment contrast under self and mixed carryover model. However, two treatment two period CODs exist for SSM. Table 2 shows optimal COD under SSM for varying number of subjects. Incidentally, optimal designs under TBM is also optimal under SSM in two treatment two period case.

From the study of Table 2, it is clear that, there are two generalized patterns in $\operatorname{COD}(2, n, 2)$ which are optimal simultaneously under TSM, TBM and SSM, $n / 4$ replications of the COD $\{\mathrm{AB}, \mathrm{BA}, \mathrm{AA}, \mathrm{BB}\}$ when $n \equiv 0(\bmod 4)$, and, $n / 4$ replications of $\{\mathrm{AB}, \mathrm{BA}, \mathrm{AA}, \mathrm{BB}\}$ augmented with single occurrence of $\{\mathrm{AB}, \mathrm{BA}\}$ when $n \equiv 2(\bmod 4)$.

\subsection{Efficient CODs under NCM, TSM, TBM and SSM}

As expected, from Table 2 it is clear that, more replications of sequences $\mathrm{AB}$ and $\mathrm{BA}$ is good for NCM while more replications of AA and BB improve estimation of three models, TSM, TBM and SSM. Accordingly, we conclude that, a COD suitable for TBM remains suitable under TSM as well as SSM. Almost all the CODs studied for optimality or efficiency consider equal replications of its sequences, most possibly for variance balancedness. This will obviously prohibit designs in unequal replications of sequences to show up. The $5 \mathrm{M}$ algorithm ensure searching every possible COD which is optimal and/or efficient under five models. The results of $5 \mathrm{M}$ algorithm are shown in Table 2. Below we discuss some interesting cases for each class defined in terms of the crucial parameter of execution, the number of subjects.

For the class $\operatorname{COD}(2,6,2)$, the $\operatorname{cod} 13\{\mathrm{AA}, 2 \mathrm{AB}, 2 \mathrm{BA}, \mathrm{BB}\}$ is efficient under NCM but optimal under TSM, TBM and SSM. When eight subjects are available, generally experimenter use two replications of design $\{\mathrm{AA}$, $\mathrm{AB}, \mathrm{BA}, \mathrm{BB}\}$ as $\operatorname{cod} 15\{2 \mathrm{AA}, 2 \mathrm{AB}, 2 \mathrm{BA}, 2 \mathrm{BB}\}$, but $\operatorname{cod} 16\{\mathrm{AA}, 3 \mathrm{AB}, 3 \mathrm{BA}, \mathrm{BB}\}$ is efficient in the class $C O D(2,8,2)$ with lesser occurrences of unlikely self repetition. Interestingly- although not surprisingly enough, the same pattern continue to hold for more classes in higher number of subjects. In the class $\operatorname{COD}(2,10,2)$, cod18\{2AA, $3 \mathrm{AB}, 3 \mathrm{BA}, 2 \mathrm{BB}\}$ and cod $19\{\mathrm{AA}, 4 \mathrm{AB}, 4 \mathrm{BA}, \mathrm{BB}\}$ perform efficient under all the models. However, cod 18 is suitable in presence of carryover, while the other one in case of no carryover. A general choice of design for the class $C O D(2,12,2)$ is to consider six replications of $\{\mathrm{AB}, \mathrm{BA}\}$, or three replications of $\{\mathrm{AB}, \mathrm{BA}, \mathrm{AA}, \mathrm{BB}\}$. As per $5 \mathrm{M}$ algorithm, both cod22 $\{2 \mathrm{AA}, 4 \mathrm{AB}, 4 \mathrm{BA}, 2 \mathrm{BB}\}$ and $\operatorname{cod} 23\{\mathrm{AA}, 5 \mathrm{AB}, 5 \mathrm{BA}, \mathrm{BB}\}$ perform efficient for all models, with former suitable under presence of carryover, and the latter in case of no carryover. Useful practical designs in the class $C O D(2,14,2)$ are $\operatorname{cod} 25\{2 \mathrm{AA}, 5 \mathrm{AB}, 5 \mathrm{BA}, 2 \mathrm{BB}\}, \operatorname{cod} 26\{\mathrm{AA}, 6 \mathrm{AB}, 6 \mathrm{BA}, \mathrm{BB}\}, \operatorname{cod} 28\{3 \mathrm{AA}, 4 \mathrm{AB}, 4 \mathrm{BA}, 3 \mathrm{BB}\}$ and $\operatorname{cod} 29\{4 \mathrm{AA}, 3 \mathrm{AB}, 3 \mathrm{BA}, 4 \mathrm{BB}\}$, with $\operatorname{cod} 25$ being the most efficient for the four models. For the class $C O D(2,16,2)$, $\operatorname{cod} 34\{4 \mathrm{AB}, 4 \mathrm{BA}, 4 \mathrm{AA}, 4 \mathrm{BB}\}$ is optimal under TSM, TBM and SSM but it has poor efficiency in case of NCM. In this class, cod31 $\{2 \mathrm{AA}, 6 \mathrm{AB}, 6 \mathrm{BA}, 2 \mathrm{BB}\}$ is efficient for all the models with equal efficiency. In class $C O D(2,18,2)$, $\operatorname{cod} 37\{2 \mathrm{AA}, 7 \mathrm{AB}, 7 \mathrm{BA}, 2 \mathrm{BB}\}$ is efficient for all the models, although not optimal under any of the models. Design $\operatorname{cod} 41\{3 \mathrm{AA}, 7 \mathrm{AB}, 7 \mathrm{BA}, 3 \mathrm{BB}\}$ is efficient under all the model for the class $\operatorname{COD}(2,20,2)$.

\section{Two treatments three period CODs}

A two treatment three period COD consists of replications of eight treatment sequences $A A A, A A B, A B A, A B B$, BAA, BAB, BBA and BBB. Due to eight treatment sequences, treatment contrast is estimable under all the models in all classes with number of choices of designs.

\subsection{Optimal CODs under NCM}

Under NCM, number of optimal designs are available. Interesting property of COD under NCM is that, the optimality of $C O D$ remains unaffected by replication of design. In other words, cod $44\{A B A, B A B\}$ is optimal for class $C O D(2,2,3)$ and $\{4 \mathrm{ABA}, 4 \mathrm{BAB}\}$ is optimal for class $\operatorname{COD}(2,8,3)$. Some new optimal CODs obtained under 
NCM are shown in Table 3. As regards other models, the new designs are more efficient than those available in the literature.

Table 3: Optimal and/or Efficient Balanced $\operatorname{COD}(2,2,3)$ to $\operatorname{COD}(2,20,3)$.

\begin{tabular}{|c|c|c|c|c|c|c|c|}
\hline $\begin{array}{l}\text { Serial } \\
\text { no. }\end{array}$ & Crossover Design & $\mathbf{n}$ & NCM & TSM & TBM & SSM & SBM \\
\hline 44 & ABA,BAB & 2 & 100 & 25 & 25 & 100 & 100 \\
\hline 45 & $\mathrm{AAB}, \mathrm{BBA}$ & 2 & 100 & 75 & 75 & - & - \\
\hline 46 & $\mathrm{ABB}, \mathrm{BAA}$ & 2 & 100 & 100 & 100 & - & - \\
\hline 47 & $\mathrm{AAB}, \mathrm{ABB}, \mathrm{BAA}, \mathrm{BBA}$ & 4 & 100 & 97 & 97 & $100^{*}$ & 75 \\
\hline 48 & $\mathrm{ABA}, \mathrm{ABB}, \mathrm{BAB}, \mathrm{BAA}$ & 4 & 100 & 81 & 81 & 72 & 80 \\
\hline 49 & $2 \mathrm{ABB}, 2 \mathrm{BAA}$ & 4 & 100 & 100 & 100 & - & - \\
\hline 50 & 2ABA,2BAB & 4 & 100 & 25 & 25 & 38 & 100 \\
\hline 51 & $\mathrm{AAB}, \mathrm{ABA}, \mathrm{ABB}, \mathrm{BAA}, \mathrm{BAB}, \mathrm{BBA}$ & 6 & 100 & 81 & 81 & 78 & 95 \\
\hline 52 & $\mathrm{AAB}, 2 \mathrm{ABB}, \mathrm{BBA}, 2 \mathrm{BAA}$ & 6 & 100 & 99 & 99 & 96 & 53 \\
\hline 53 & 2ABA,ABB,2BAB,BAA & 6 & 100 & 67 & 67 & 62 & $100^{@}$ \\
\hline 54 & $\mathrm{ABA}, 2 \mathrm{ABB}, \mathrm{BAB}, 2 \mathrm{BAA}$ & 6 & 100 & 92 & 92 & $100^{*}$ & 59 \\
\hline 55 & 3ABB,3BAA & 6 & 100 & 100 & 100 & - & - \\
\hline 56 & 2AAB,2ABB,2BAA,2BBA & 8 & 100 & 97 & 97 & 77 & 62 \\
\hline 57 & АAB,AВA,2АВВ,2ВАA,ВАВ,ВBA & 8 & 100 & 90 & 90 & 70 & 99 \\
\hline 58 & $\mathrm{AAB}, 3 \mathrm{ABB}, 3 \mathrm{BAA}, \mathrm{BBA}$ & 8 & 100 & 99 & 99 & $100^{*}$ & 44 \\
\hline 59 & AAA,AAB,ABA,ABB,BAA,BAB,BBA,BBB & 8 & 75 & 63 & 63 & 50 & $100^{@}$ \\
\hline 60 & $4 \mathrm{ABB}, 4 \mathrm{BAA}$ & 8 & 100 & 100 & 100 & - & - \\
\hline 61 & $\mathrm{AAB}, 4 \mathrm{ABB}, 4 \mathrm{BAA}, \mathrm{BBA}$ & 10 & 100 & $100^{\bullet}$ & $100^{\bullet}$ & 94 & 33 \\
\hline 62 & 2АAB,3АВВ,3ВАA,2BBA & 10 & 100 & 98 & 98 & $100^{*}$ & 71 \\
\hline 63 & $\mathrm{AAA}, 2 \mathrm{ABA}, 2 \mathrm{ABB}, 2 \mathrm{BAA}, 2 \mathrm{BAB}, \mathrm{BBB}$ & 10 & 80 & 66 & 66 & 66 & $100^{@}$ \\
\hline 64 & 2АAB,АВA,3АВВ,3ВAA,ВАВ,2ВBA & 12 & 100 & 93 & 93 & 92 & 94 \\
\hline 65 & $2 \mathrm{AAB}, 4 \mathrm{ABB}, 4 \mathrm{BAA}, 2 \mathrm{BBA}$ & 12 & 100 & 99 & 99 & $100^{*}$ & 40 \\
\hline 66 & $\mathrm{AAB}, 5 \mathrm{ABB}, 5 \mathrm{BAA}, \mathrm{BBA}$ & 12 & 100 & $100^{\bullet}$ & $100^{\bullet}$ & 90 & 33 \\
\hline 67 & $3 \mathrm{AAB}, 3 \mathrm{ABA}, 3 \mathrm{BAB}, 3 \mathrm{BBA}$ & 12 & 100 & 50 & 50 & 45 & 100 \\
\hline 68 & 3AAA,4ABB,BAA,3BAB,3BBA & 14 & 94 & $100^{\bullet}$ & $100^{\bullet}$ & 76 & 60 \\
\hline 69 & 3АAB, 4 ABB $, 4 \mathrm{BAA}, 3 \mathrm{BBA}$ & 14 & 100 & 93 & 93 & $100^{*}$ & 80 \\
\hline 70 & 2AAA,2AAB,2ABA,ABB,BAA,2BAB,2BBA,2BBB & 14 & 71 & 51 & 51 & 76 & $100^{@}$ \\
\hline 71 & 2AAA,3АBA,3АBB,BAA,5BAB,2BBA & 16 & 87 & 92 & 92 & 58 & 92 \\
\hline 72 & ЗАAB,5АBВ,5BAA,3BBA & 16 & 100 & 98 & 98 & 73 & 67 \\
\hline 73 & АAB,ABA,6ABB,6BAA, ВAB, ВBA & 16 & 100 & 98 & 98 & 63 & 76 \\
\hline 74 & $8 \mathrm{ABB}, 8 \mathrm{BAA}$ & 16 & 100 & 100 & 100 & - & - \\
\hline 75 & 3AAA,ABA,4ABB,BAA,4BAB,3BBA & 16 & 81 & 84 & 84 & $100^{*}$ & 75 \\
\hline 76 & 3AAA,3AAB,2ABB,3BBB,3BBA,2BAA & 16 & 63 & 60 & 60 & 44 & $100^{\circledR}$ \\
\hline 77 & $4 \mathrm{AAB}, \mathrm{ABA}, 4 \mathrm{ABB}, 4 \mathrm{BAA}, \mathrm{BAB}, 4 \mathrm{BBA}$ & 18 & 100 & 89 & 86 & 75 & 70 \\
\hline 78 & $\mathrm{AAA}, 2 \mathrm{AAB}, 5 \mathrm{ABA}, \mathrm{ABB}, 3 \mathrm{BAA}, 3 \mathrm{BAB}, 3 \mathrm{BBB}$ & 18 & 78 & $100^{\bullet}$ & 58 & 46 & 69 \\
\hline 79 & 3AAB,6ABA,3BAA,3BAB,3BBB & 18 & 83 & 51 & $100^{\bullet}$ & 27 & 62 \\
\hline 80 & $5 \mathrm{AAA}, 4 \mathrm{ABB}, 4 \mathrm{BAB}, 4 \mathrm{BBA}, \mathrm{BBB}$ & 18 & 67 & 75 & 73 & $100^{*}$ & 49 \\
\hline 81 & $2 \mathrm{AAA}, 3 \mathrm{AAB}, 4 \mathrm{ABB}, 4 \mathrm{BAA}, 3 \mathrm{BBA}, 2 \mathrm{BBB}$ & 18 & 78 & 73 & 70 & 65 & $100^{@}$ \\
\hline 82 & $\mathrm{AAA}, 4 \mathrm{AAB}, \mathrm{ABA}, 4 \mathrm{ABB}, 4 \mathrm{BAA}, \mathrm{BAB}, 4 \mathrm{BBA}, \mathrm{BBB}$ & 20 & 90 & 79 & 81 & 86 & 39 \\
\hline 83 & 3АAB,3АВA,4ABB,4BAA,3ВAB,3ВBA & 20 & 100 & 81 & 82 & 59 & 52 \\
\hline 84 & 3АAB,7ABB,7BAA,3BBA & 20 & 100 & 94 & 96 & 69 & 40 \\
\hline 85 & 8AAB,2ABA,2BAA,6BBA,2BBB & 20 & 90 & $100^{\bullet}$ & 86 & 21 & 28 \\
\hline 86 & 6AAB,3ABA,ABB,4BAA,3BBA,3BBB & 20 & 85 & 70 & $100^{\bullet}$ & 33 & 33 \\
\hline 87 & 4AAA,3AAB,3ABB,BAA,2BAB,5BBA,2BBB & 20 & 70 & 59 & 60 & $100^{*}$ & 35 \\
\hline
\end{tabular}


Design in bold denote new optimal and/or efficient COD to class having $n$ number of subjects

${ }^{*}$ New Optimal COD under new defined model SSM

@ New Optimal COD under SBM

- New Optimal COD under TSM and/or TBM

\subsection{Optimal CODs under TSM and TBM}

Because of combinatorial properties, CODs that are optimal under TBM are also optimal under TSM for $n \leq$ 16. Beyond this value, optimal designs differ with change of models. In the class $C O D(2,18,3)$, cod78 \{AAA, $2 \mathrm{AAB}, 5 \mathrm{ABA}, \mathrm{ABB}, 3 \mathrm{BAA}, 3 \mathrm{BAB}, 3 \mathrm{BBB}$ \} is optimal under TSM and its efficiency is $58 \%$ under TBM, whereas cod79\{3AAB, 6ABA, 3BAA, 3BAB, 3BBB $\}$ is optimal under TBM and its efficiency is $51 \%$ under TSM. Similarly, in the class $\operatorname{COD}(2,20,3)$, cod $85\{8 \mathrm{AAB}, 2 \mathrm{ABA}, 2 \mathrm{BAA}, 6 \mathrm{BBA}, 2 \mathrm{BBB}\}$ is optimal under TSM, and its efficiency is $86 \%$ under TBM whereas cod $86\{6 \mathrm{AAB}, 3 \mathrm{ABA}, \mathrm{ABB}, 4 \mathrm{BAA}, 3 \mathrm{BBA}, 3 \mathrm{BBB}\}$ is optimal under TBM and its efficiency is $70 \%$ under TSM.

As per literature, $\operatorname{cod} 49\{2 \mathrm{ABB}, 2 \mathrm{BAA}\}, \operatorname{cod} 55\{3 \mathrm{ABB}, 3 \mathrm{BAA}\}, \operatorname{cod} 60\{4 \mathrm{ABB}, 4 \mathrm{BAA}\}$ and, $\operatorname{cod} 74\{8 \mathrm{ABB}, 8 \mathrm{BAA}\}$ are optimal under both TSM and TBM, respectively for the classes $\operatorname{COD}(2,2,3), \operatorname{COD}(2,4,3), \operatorname{COD}(2,6,3), \operatorname{COD}(2,8,3)$ and $\operatorname{COD}(2,16,3)$. However, these designs are unable to estimate treatment under SSM and SBM. Note that, 5M algorithm fills both the gaps, it provides unavailable CODs as well as those estimable under SSM and SBM. Table 3 lists algorithm generated optimal CODs for classes $\operatorname{COD}(2,10,3), \operatorname{COD}(2,12,3)$ and $\operatorname{COD}(2,14,3)$ under TBM and $\mathrm{TSM}$, they are respectively cod61 $\{\mathrm{AAB}, 4 \mathrm{ABB}, 4 \mathrm{BAA}, \mathrm{BBA}\}, \operatorname{cod} 66\{\mathrm{AAB}, 5 \mathrm{ABB}, 5 \mathrm{BAA}, \mathrm{BBA}\}$ and cod68 $\{3 \mathrm{AAA}$, $4 \mathrm{ABB}, \mathrm{BAA}, 3 \mathrm{BAB}, 3 \mathrm{BBA}\}$.

\subsection{Optimal CODs under SSM}

Self and mixed carryover model and its optimal design is frequently discussed in optimal design literature which as per our terminology falls under the case SBM. This is the first attempt to give optimal designs under SSM. From Table 3, it is clear that unlike two period CODs, a three period design that is optimal under SSM is not necessarily optimal under SBM. In every class, design optimal under SSM is generally different than the design optimal under SBM. Moreover, unlike two period designs which could be replicated easily and remain optimal on availability of more subjects, for a three period design the sequences must be planned exclusively. For example, in class $\operatorname{COD}(2,4,3)$, cod47 $\{\mathrm{AAB}, \mathrm{ABB}, \mathrm{BAA}, \mathrm{BBA}\}$ is optimal and not $\operatorname{cod} 50\{2 \mathrm{ABA}, 2 \mathrm{BAB}\}$.

\subsection{Optimal CODs under SBM}

Optimal design literature has shown that $\left\{\frac{n}{2} \mathrm{ABA}, \frac{n}{2} \mathrm{BAB}\right\}$, that is, the design in which half the subjects receive sequence $\mathrm{ABA}$ and the other half receive $\mathrm{BAB}$ is optimal under SBM. However, this design is optimal only for the classes $\operatorname{COD}(2,2,3)$ and $\operatorname{COD}(2,4,3)$ and not in general for $\operatorname{COD}(2, n, 3)$ with arbitrary $n(n \equiv 0(\bmod 2))$. Note that, FDA [13] have suggested to use such designs for bioequivalence studies. Through $5 \mathrm{M}$ algorithm we have obtained optimal $\operatorname{COD}(2, n, 3)$ for $n=6,8,10, \ldots, 20$. The new designs do not require strict pattern to be followed, rather they provide higher amount of randomness. As for example, the optimal design for the class $\mathrm{COD}(2,6,3)$, under $\mathrm{SBM}$ is cod53 $\{2 \mathrm{ABA}, \mathrm{ABB}, 2 \mathrm{BAB}, \mathrm{BAA}\}$, it uses four out of eight sequences. Among designs having all treatment sequences cod59 $\{\mathrm{AAA}, \mathrm{AAB}, \mathrm{ABA}, \mathrm{ABB}, \mathrm{BAA}, \mathrm{BAB}, \mathrm{BBA}, \mathrm{BBB}\}$ is optimal under SBM for $\operatorname{COD}(2,8,3)$. For the class $C O D(2,10,3)$, cod63\{AAA, 2ABA, 2ABB, 2BAA, 2BAB, BBB\} is optimal under SBM. Three replications of design $\{\mathrm{AAB}, \mathrm{ABA}, \mathrm{BAB}, \mathrm{BBA}\}$ as cod67 $\{3 \mathrm{AAB}, 3 \mathrm{ABA}, 3 \mathrm{BAB}, 3 \mathrm{BBA}\}$ is optimal under $\mathrm{SBM}$ for $\operatorname{COD}(2,12,3)$. Note that $\{\mathrm{AAB}, \mathrm{ABA}, \mathrm{BAB}, \mathrm{BBA}\}$ is not optimal for the class $C O D(2,4,3)$.

For most of the classes, design optimal under SBM contains sequences AAA and BBB. Inclusion of these sequences in design decrease the variance of treatment contrast under SBM but increase the same under NCM. Consequently, designs having these sequences is not optimal under NCM. For example, designs cod70\{2AAA, $2 \mathrm{AAB}, 2 \mathrm{ABA}, \mathrm{ABB}, \mathrm{BAA}, 2 \mathrm{BAB}, 2 \mathrm{BBA}, 2 \mathrm{BBB}\}, \operatorname{cod} 76\{3 \mathrm{AAA}, 3 \mathrm{AAB}, 2 \mathrm{ABB}, 3 \mathrm{BBB}, 3 \mathrm{BBA}, 2 \mathrm{BAA}\}$ and cod81\{2AAA, $3 \mathrm{AAB}, 4 \mathrm{ABB}, 4 \mathrm{BAA}, 3 \mathrm{BBA}, 2 \mathrm{BBB}\}$ respectively of classes $\operatorname{COD}(2,14,3), \operatorname{COD}(2,16,3)$ and $\operatorname{COD}(2,18,3)$ are optimal under SBM, but not so under NCM. For a design to be optimal under both models, NCM as well as SBM, it should not contain sequences AAA and BBB. This is illustrated by designs cod67 and cod88 $\{9 \mathrm{ABA}, \mathrm{ABB}, \mathrm{BAA}$, $9 \mathrm{BAB}\}$ respectively for classes $\operatorname{COD}(2,12,3)$ and $\operatorname{COD}(2,20,3)$. All the designs mentioned in this section for $8 \leq$ $n \leq 20$ are new optimal COD for the respective classes. 


\subsection{Efficient CODs under NCM, TSM, TBM, SSM and SBM}

An FDA [13] guideline has suggested to use $\left\{\frac{n}{2} \mathrm{ABA}, \frac{n}{2} \mathrm{BAB}\right\}$ for two treatment three period case experiment. However, this design has poor efficiency under TBM. Noticing this, Hedayat and Stufken [8] have suggested to use cod51 $\{\mathrm{AAB}, \mathrm{ABA}, \mathrm{ABB}, \mathrm{BAA}, \mathrm{BAB}, \mathrm{BBA}\}$ instead, because their design is optimal under NCM and efficient under both the TBM and SBM. But this last design is efficient only in the class $C O D(2,6,3)$. In other classes, that is, for $n>6$, other designs are more efficient. In class $\operatorname{COD}(2,8,3)$, cod57\{AAB, $\mathrm{ABA}, 2 \mathrm{ABB}, 2 \mathrm{BAA}, \mathrm{BAB}, \mathrm{BBA}\}$ is optimal under NCM and efficient under TSM, TBM, SSM and SBM. This design is even more efficient than the one resulting from replication of cod47, that is, cod56 $22 \mathrm{AAB}, 2 \mathrm{ABB}, 2 \mathrm{BAA}, 2 \mathrm{BBA}\}$. Design cod62 $2 \mathrm{AAB}, 3 \mathrm{ABB}$, 3BAA, $2 \mathrm{BBA}\}$ is better choice for class $\operatorname{COD}(2,10,3)$ as compared to repeating $C O D(2,2,3)$ five times. In class $\operatorname{COD}(2,12,3), \operatorname{cod} 65\{2 \mathrm{AAB}, 4 \mathrm{ABB}, 4 \mathrm{BAA}, 2 \mathrm{BBA}\}$ is better choice when there is less possibility of SBM because this design is nearly optimal under NCM, TSM, TBM, SSM simultaneously. In other cases, experimenter should use $\operatorname{cod} 64\{2 \mathrm{AAB}, \mathrm{ABA}, 3 \mathrm{ABB}, 3 \mathrm{BAA}, \mathrm{BAB}, 2 \mathrm{BBA}\}$, because it is efficient for all the models. In class $C O D(2,14,3)$, two designs perform well. Specifically speaking, when there is more possibility of TSM and TBM then experimenter should use cod68\{3AAA, 4ABB, BAA, 3BAB, 3BBA\} design because it optimal under both models and efficient under other model, and otherwise, should use cod69\{3AAB, 4ABB, 4BAA, 3BBA\} because it optimal under NCM and SSM and efficient under the remaining models. In class $\operatorname{COD}(2,16,3)$, although number of choices of designs are available as repetition of smaller designs, but the two computer generated designs cod72\{3AAB, 5ABB, 5BAA, 3BBA $\}$ and cod73 $\{\mathrm{AAB}, \mathrm{ABA}, 6 \mathrm{ABB}, 6 \mathrm{BAA}, \mathrm{BAB}, \mathrm{BBA}\}$ give optimal estimation of treatment contrast under NCM and efficient under the remaining four models. This design has very high efficiency of $98 \%$ in the cases of TSM and TBM. A further example of design having six sequences cod77\{4AAB, ABA, 4ABB, 4BAA, $\mathrm{BAB}, 4 \mathrm{BBA}$ \} with unequal weights, is optimal under $\mathrm{NCM}$ and efficient under the remaining four models for class $\operatorname{COD}(2,18,3)$.

\section{Two treatment four period CODs}

The possible combinations of two treatments in four periods have sixteen treatment sequences, $\mathrm{AAAA}, \mathrm{AAAB}$, AABA, AABB, ABAA, ABAB, ABBA, ABBB, BAAA, BAAB, BABA, BABB, BBAA, BBAB, BBBA and BBBB. Here two treatment sequences $A A A A$ and $B B B B$ repeatedly use same treatment in four periods. It is harmful to give the same experimental drug to patient repeatedly four times. Therefore, treatment sequences AAAA and BBBB are not included in the construction of two treatment four period designs.

\subsection{Optimal CODs under NCM, TSM, TBM and SSM}

Optimal COD literature has shown that the cod95\{AABB, ABBA, BAAB, BBAA\} is optimal under NCM and TBM for two treatment four period case. However it needs at least four units. For the class $C O D(2,2,4)$, cod $90\{\mathrm{AABB}, \mathrm{BBAA}\}$ is optimal under NCM, TSM and TBM, and, cod92\{ABAB, BABA\} is optimal under SSM and SBM. Replication of $\operatorname{cod} 95\{\mathrm{AABB}, \mathrm{ABBA}, \mathrm{BAAB}, \mathrm{BBAA}\}$ as $\left\{\frac{n}{4} \mathrm{AABB}, \frac{n}{4} \mathrm{ABBA}, \frac{n}{4} \mathrm{BAAB}, \frac{n}{4} \mathrm{BBAA}\right\}$ is optimal under NCM, TSM, TBM and SSM when $n \equiv 0(\bmod 4)$. In other cases when the number of subjects is not in multiple of four, replicating do not yield optimal design. Table 4 show that, designs cod98\{AABB, 2ABBA, 2BAAB, BBAA\}, cod103\{3AABB, 2ABBA, 2BAAB, 3BBAA\}, cod109\{3AABB, 4ABBA, 4BAAB, 3BBAA\} and cod114\{4AABB, 5ABBA, 5BAAB, 4BBAA\} are optimal under NCM, TSM and TBM respectively for the classes $\operatorname{COD}(2,6,4), \operatorname{COD}(2,10,4), \operatorname{COD}(2,14,4)$ and $\operatorname{COD}(2,18,4)$. However, cod99\{2AABB, ABBA, BAAA, BBAA, BBAB\}, $\operatorname{cod} 105\{3 \mathrm{AABB}, 2 \mathrm{ABBA}, \mathrm{BAAA}, \mathrm{BAAB}, 2 \mathrm{BBAA}, \mathrm{BBAB}\}, \operatorname{cod} 110\{4 \mathrm{AABB}, 3 \mathrm{ABBA}, \mathrm{BAAA}, 2 \mathrm{BAAB}, 3 \mathrm{BBAA}, \mathrm{BBAB}\}$ and cod115\{4AABB, 5ABBA, BAAA, 4BAAB, 3BBAA, BBAB\} are optimal under SSM for classes COD $(2,6,4)$, $\operatorname{COD}(2,10,4), \operatorname{COD}(2,14,4)$ and $\operatorname{COD}(2,18,4)$ respectively.

Table 4: Optimal and/or Efficient Balanced $\operatorname{COD}(2,2,4)$ to $\operatorname{COD}(2,20,4)$.

\begin{tabular}{llllllll}
\hline Serial & Crossover Design & $\mathbf{n}$ & NCM & TSM & TBM & SSM & SBM \\
\hline 89 & AABA,BBAB & 2 & 75 & 60 & 60 & 92 & 92 \\
90 & AABB,BBAA & 2 & 100 & 100 & 100 & 92 & 92 \\
91 & ABAA,BABB & 2 & 75 & 60 & 60 & 92 & 92 \\
92 & ABAB,BABA & 2 & 100 & 20 & 20 & 100 & 100 \\
93 & ABBA,BAAB & 2 & 100 & 100 & 100 & 92 & 92
\end{tabular}




\begin{tabular}{|c|c|c|c|c|c|c|c|}
\hline 94 & 2AABB,2BBAA & 4 & 100 & 91 & 91 & 28 & 89 \\
\hline 95 & $\mathrm{AABB}, \mathrm{ABBA}, \mathrm{BAAB}, \mathrm{BBAA}$ & 4 & 100 & 100 & 100 & $100^{*}$ & 97 \\
\hline 96 & AABB,ABBA,BAAA,BBAB & 4 & 88 & 87 & 87 & $100^{*}$ & 96 \\
\hline 97 & ABAA,ABBA,BAAB,BABB & 4 & 88 & 73 & 73 & 76 & 100 \\
\hline 98 & AABB,2ABBA,2BAAB,BBAA & 6 & 100 & $100^{\bullet}$ & $100^{\bullet}$ & 99 & 97 \\
\hline 99 & 2AABB,ABBA,BAAA,BBAA,BBAB & 6 & 92 & 92 & 92 & $100^{*}$ & 96 \\
\hline 100 & AABB,ABAA,ABBA,BAAB,BABB,BBAA & 6 & 92 & 90 & 90 & 91 & $100^{\circledR}$ \\
\hline 101 & 2AABB,2ABBA,2BAAB,2BBAA & 8 & 100 & 100 & 100 & 100 & 97 \\
\hline 102 & 2ABAA,2ABBA,2BAAB,2BABB & 8 & 88 & 73 & 73 & 76 & 100 \\
\hline 103 & 3ААВВ,2АВВА,2ВААВ,3ВВАA & 10 & 100 & $100^{\bullet}$ & $100^{\bullet}$ & 99 & 97 \\
\hline 104 & 2AABB,3АBBA,3ВАAB,2BBAA & 10 & 100 & 100 & 100 & 99 & 97 \\
\hline 105 & 3АABВ,2АВВА,ВAAA,BAAB,2BBAA,ВBAB & 10 & 95 & 95 & 95 & $100^{*}$ & 97 \\
\hline 106 & 2AABA,ABAB,2ABBA,2BAAB,BABA,2BBAB & 10 & 90 & 67 & 67 & 72 & $100^{\circledR}$ \\
\hline 107 & 3АABВ,3АВВА,3ВААВ,3ВВАA & 12 & 100 & 100 & 100 & 100 & 97 \\
\hline 108 & 3АВАA,3АВВА,3ВААВ,3ВАВВ & 12 & 88 & 73 & 73 & 76 & 100 \\
\hline 109 & 3АAВВ,4АВBA,4ВАAB,3ВВАA & 14 & 100 & $100^{\bullet}$ & $100^{\bullet}$ & 99 & 97 \\
\hline 110 & 4AABB,3АBВA,BAAA,2BAAB,3BВAA,BBAB & 14 & 96 & 97 & 97 & $100^{*}$ & 97 \\
\hline 111 & 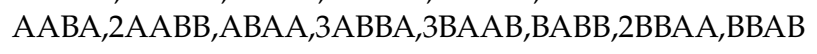 & 14 & 93 & 90 & 90 & 93 & $100^{\circledR}$ \\
\hline 112 & 4AABB,4ABBA,4BAAB,4BBAA & 16 & 100 & 100 & 100 & 100 & 97 \\
\hline 113 & 4ABAA,4ABBA,4BAAB,4BABB & 16 & 88 & 73 & 73 & 76 & 100 \\
\hline 114 & 4АABВ,5АВВА,5ВАAB,4ВBAA & 18 & 100 & $100^{\bullet}$ & $100^{\bullet}$ & 99 & 97 \\
\hline 115 & 4AABB,5ABBA,BAAA,4BAAB,3BВAA,BBAB & 18 & 97 & 97 & 97 & $100^{*}$ & 97 \\
\hline 116 & 4AABA, $\mathrm{ABAB}, 4 \mathrm{ABBA}, 4 \mathrm{BAAB}, \mathrm{BABA}, 4 \mathrm{BBAB}$ & 18 & 89 & 70 & 70 & 73 & $100^{\circledR}$ \\
\hline 117 & 5AABВ,5АВBA,5BAAB,5BВAА & 20 & 100 & 100 & 100 & 100 & 97 \\
\hline 118 & 5ABAA,5АBBA,5BAAB,5BABВ & 20 & 88 & 73 & 73 & 76 & 100 \\
\hline
\end{tabular}

Design in bold denote new optimal and/or efficient COD to class having $n$ number of subjects

* New Optimal COD under new defined model SSM

${ }^{\circledR}$ New Optimal COD under SBM

- New Optimal COD under TSM and TBM

\subsection{Optimal CODs under SBM}

Optimal two treatment four period CODs given by Hedayat and Stufken [8] are useful only when availability of subjects is eight. Also their designs are obtained using the weight restriction $w 4=3 w 1+w 2+w 3$. Because of this restriction some designs may not get opportunity to show up. Crossover designs obtained through the $5 \mathrm{M}$ Algorithm covers all possible designs. Optimal COD for the case when $n \equiv 0(\bmod 4)$ is replication of $\operatorname{cod} 97\{\mathrm{ABAA}, \mathrm{ABBA}, \mathrm{BAAB}, \mathrm{BABB}\}$ as $\left\{\frac{n}{4} \mathrm{ABAA}, \frac{n}{4} \mathrm{ABBA}, \frac{n}{4} \mathrm{BAAB}, \frac{n}{4} \mathrm{BABB}\right\}$. However, there is no generalized pattern for optimal $C O D$ in the case $n \equiv 2(\bmod 4)$. Let us discuss one by one. For the class $C O D(2,6,4), 5 \mathrm{M}$ Algorithm gives a cod $100\{\mathrm{AABB}, \mathrm{ABAA}, \mathrm{ABBA}, \mathrm{BAAB}, \mathrm{BABB}, \mathrm{BBAA}\}$ which has lesser variance than the comparable $\mathrm{COD}\{\mathrm{AABB}, \mathrm{ABAB}, \mathrm{ABBA}, \mathrm{BAAB}, \mathrm{BABA}, \mathrm{BBAA}\}$ in six sequences of Ozan and Stufken [9] and hence cod100 is now optimal design in this class. In other classes, $C O D(2,10,4), C O D(2,14,4)$ and $C O D(2,18,4)$, CODs optimal under SBM are respectively, cod106\{2AABA, ABAB, 2ABBA, 2BAAB, BABA, 2BBAB\}, cod111\{AABA, 2AABB, ABAA, 3ABBA, 3BAAB, BABB, 2BBAA, BBAB $\}$ and cod116 $44 \mathrm{AABA}, \mathrm{ABAB}, 4 \mathrm{ABBA}, 4 \mathrm{BAAB}, \mathrm{BABA}, 4 \mathrm{BBAB}\}$. Note that, cod92 $\{\mathrm{ABAB}, \mathrm{BABA}\}$ is the well known optimal $C O D$ for $C O D(2,2,4)$. 


\subsection{Efficient CODs under NCM, TSM, TBM, SSM and SBM}

There exist two generalized patterns among efficient CODs, particulary for even number of subjects. One is replication of $\operatorname{cod} 95\{\mathrm{AABB}, \mathrm{ABBA}, \mathrm{BAAB}, \mathrm{BBAA}\}$ as $\left\{\frac{n}{4} \mathrm{AABB}, \frac{n}{4} \mathrm{ABBA}, \frac{n}{4} \mathrm{BAAB}, \frac{n}{4} \mathrm{BBAA}\right\}$ is efficient under NCM, TSM, TBM, SSM and SBM when $n \equiv 0(\bmod 4)$. Secondly, when $n \equiv 2(\bmod 4), n / 4$ replications of $\{$ AABB, ABBA, BAAB, BBAA $\}$ augmented with single occurrence of $\{$ ABBA, BAAB $\}$ is efficient for NCM, TSM, TBM, SSM and SBM. Note that, cod93 $\{\mathrm{ABBA}, \mathrm{BAAB}\}$ is the well known optimal COD for $C O D(2,2,4)$.

\section{Conclusion}

Several new two treatment crossover designs have been contributed for five types of carryover models. The introduction of two new forms of carryover models resulted in detailed characterization of existing and new two treatment crossover designs. The computer program for the $5 \mathrm{M}$ algorithm costs time for not missing a single optimal crossover design. It is a general purpose algorithm and can be used for generating designs in more than twenty subjects, not listed in this article. Experimenters will now have more flexibility in choice of two treatment crossover designs, in terms of, number of subjects, number of repeated measurements, and handling carryover of treatments. We recommend that, an optimal design should be chosen when one is sure about the model. Otherwise, one should opt for a design which is efficient for all five models.

\section{References}

[1] Senn S. Is the simple carryover model useful? Stat Med. 1992;11:715-26.

[2] Senn S, Lambrou D. Robust and realistic approach to carry-over. Stat Med 1998;17:2849-64.

[3] R. Kempton SF, David O. Optimal change-over designs when carry-over effects are proportional to direct effects of treatments. Biometrika 2001;88:391-9.

[4] Jones B, Donev A. Modelling and design of cross-over trials. Stat Med. 1996;15:1435-46.

[5] ]. John KR, Whitaker D. Crossover: an algorithm for the construction of efficient cross-over designs. Stat Med. 2004;23:2645-58.

[6] Yang M, Stufken ]. Optimal and efficient crossover designs for comparing test treatments to a control treatment under various models. ] Stat Plan Infer. 2008;138:278-85.

[7] S. Satpati RP, Cupta V, Aggarwal M. Computer-generated change-over designs for correlated observations. Commun Stat-Theo Meth. 2012;41:3786-98.

[8] Hedayat A, Stufken ]. Optimal and efficient crossover designs under different assumptions about the carryover effects. ] Biopharm Stat. 2003;13:519-28.

[9] Ozan M, Stufken ]. Assessing the impact of carryover effects on the variances of estimators of treatment differences in crossover designs. Stat Med. 2010;29:2480-5.

[10] Afsarinejad K, Hedayat A. Repeated measurements designs for a model with self and mixed carryover effects. ] Stat Plan Infer. 2002;106:449-59.

[11] Kunert ], Stufken ]. Optimal crossover designs in a model with self and mixed carryover effects. ] Am Stat Assoc 2002;97:898-906.

[12] Kunert ], Stufken ]. Optimal crossover designs for two treatments in the presence of mixed and self carryover effects. ] Am Stat Assoc. 2008;103:1641-7.

[13] FDA. Guidance for Industry: Statistical Approaches to Establishing Bioequivalence. Food and Drug Administration: Centerfor Drug Evaluation and Research (CDER): US Department of Health and Human Services, 2001. 